\title{
Numerical Prediction of Vadose Zone Behaviour Influenced by Vegetation
}

\author{
B.Indraratna ${ }^{1}$, B.Fatahi ${ }^{2}$, and H.Khabbaz ${ }^{3}$ \\ ${ }^{1}$ Professor of Civil Engineering, University of Wollongong, NSW 2522, Australia; \\ email: indra@uow.edu.au \\ ${ }^{2} \mathrm{PhD}$ Candidate, Civil Engineering, University of Wollongong, NSW 2522, Australia; \\ email: behzad@uow.edu.au \\ ${ }^{3}$ Research Fellow, Civil Engineering, University of Wollongong, NSW 2522, \\ Australia; email: khabbaz@uow.edu.au
}

\begin{abstract}
Bioengineering aspects of native vegetation are currently, and rapidly, being evolved to improve soil stiffness, slope stabilisation, and erosion control. Apart from the reinforcement effect, tree roots establish sufficient matric suction to increase the shear strength and stiffness of the soil. This paper looks at the way, vegetation influences soil matric suction, shrinkage, and ground settlement. A mathematical model for the rate of root water uptake that considers ground conditions, type of vegetation and climatic parameters, has been developed. Based on this proposed model, the distribution of moisture and the matric suction profile adjacent to the tree are numerically analysed. The model formulation is based on the general effective stress theory of unsaturated soils. Field measurements taken from literature published previously are compared with the authors' numerical model. The predicted results calculated using the soil, plant, and atmospheric parameters contained in the numerical model, compared favourably with the measured results, justifying the assumptions upon which the model was developed.
\end{abstract}

\section{Introduction}

Population increases over the past decades have necessitated constructing infrastructure on soft and expansive soils. For example, in Australia, rail corridors have often been built on soft, compressive formations, or expansive clays. Some new maintenance observations of Australian tracks show that wherever there are trees beside them, their localised, undrained failure is less (Figure 1). However, analysing 
and designing shallow foundations located on the vadose zone in the vicinity of native vegetation remains a challenge to geotechnical engineers.

Available studies indicate that most attempts to quantify the effects of vegetation have focused on the structural reinforcement provided by the roots, while almost no attempt has been made to relate changes of soil strength and stiffness to the rate of transpiration. Although it is believed that these reinforcements increase cohesion and the modulus of elasticity (Docker \& Hubble, 2001), changes in soil suction induced by the roots have not been considered in detail in previous models. As described by McKeen (1992), trees can provide suction up to $1550-3100 \mathrm{kPa}$, which is the wilting point of a soil-root system and therefore, ground consolidation associated with transpiration increases soil strength and stiffness. This process may be compared with improving soft soil via prefabricated vertical drains and vacuum preloading. The suction induced by transpiration increases the effective stresses, which in turn increases the settlement and stiffness of unsaturated soil.

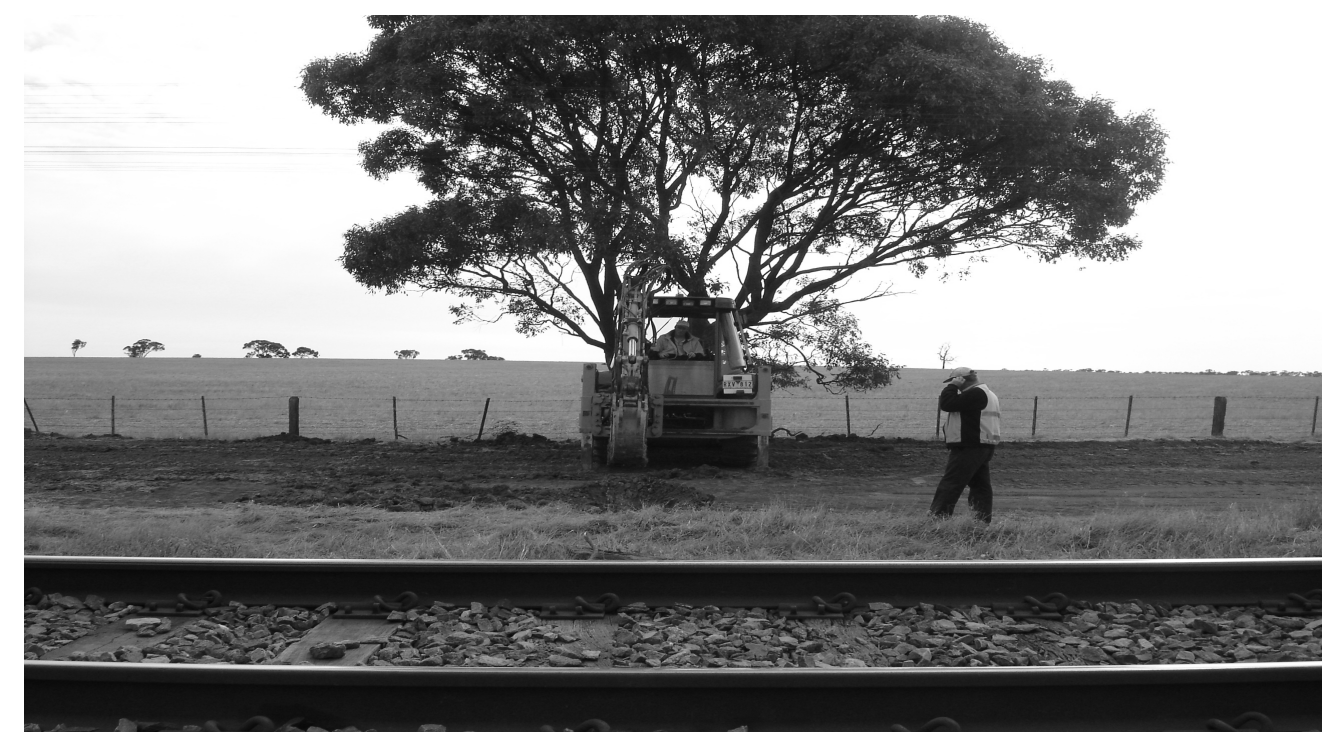

Figure 1. Photo during investigation of influence of a Black Box tree on rail track, Miram, Victoria, Australia

Transpiration due to tree roots is a continuous process of discharging water from the soil matrix via the tree canopy. Although it is well known that high rainfall and infiltration can rapidly reduce suction, Zhang et al. (2004) showed that rainfall does not necessarily eliminate suction in the soil. Therefore, for a more economical design of structures in vegetated ground, the effect of matric suction induced by tree roots on shear strength and deformation of partially saturated soil needs to be considered. Soil conditions, type of vegetation, and atmospheric conditions affect the rate of root water uptake and hence, transpiration. Consequently, any model, which can realistically calculate the rate of root water uptake, must capture the true interaction between the above features. A finite element analysis is used in this study to predict the distribution of moisture, and the suction profile based on the proposed governing equations but it does require an accurate estimation of various parameters based on careful field observations. 


\section{Conceptual model for root water uptake}

The main factor for estimating the rate of transpiration is the rate of root water uptake, which in turns depends on the geological, hydrological, and meteorological conditions, hence:

$T(t)=\int_{V(t)} S(x, y, z, t) d V$

where, $T(t)$ is the transpiration rate at time $t, S(x, y, z, t)$ is the rate of the root water uptake at point $(x, y, z)$ at time $\mathrm{t}$, and if $V(t)$ is the volume of root zone at time $\mathrm{t}, d V$ denotes a small volumetric change.

The details of each single root and its interaction with the surrounding soil is required to identify the microscopic interaction between the soil and root system. In this study a macroscopic approach is adopted, which considers the integrated properties of the entire root system, assuming that both the soil and roots form a continuous media. Therefore, the root water uptake is considered as a volumetric sink term in the flow continuity equation, which can be defined as the volume of water extracted per unit bulk volume of soil per unit time. The soil water flow differential equation, including the sink term, $S(x, y, z, t)$, can then be written as:

$\frac{\partial \theta}{\partial t}=\nabla \cdot(k \nabla \psi)-\frac{\partial k}{\partial z}-S(x, y, z, t)$

where, $\theta\left(=V_{W} / V\right)$ is the volumetric moisture content, ( $V_{w}=$ volume of water, $V=$ total volume), $\nabla$ is the divergence vector, $\psi$ is the soil suction, $k$ is the hydraulic conductivity, and $z$ is the vertical coordinate (downward is positive).

The soil suction, root density distribution, and potential transpiration, which are three independent features, may be combined to establish an appropriate analytical solution for estimating the rate of root water uptake. Thus, it can be assumed that the rate of root water uptake can be expressed as three separate functions of the independent features. As suggested by Indraratna et al. (2005), it can be assumed that:

$S(x, y, z, t)=f(\psi) \cdot G(\beta) \cdot F\left(T_{P}\right)$

where, $G(\beta)$ is the root density factor, $f(\psi)$ is the soil suction factor, and $F\left(T_{P}\right)$ is the potential transpiration factor.

To calculate $f(\psi)$, different approaches have been recommended by various researchers. The simplified equation suggested by Feddes et al. (1978) is used to determine the effect of suction. The relationship suggested for $f(\psi)$, indicated by Feddes et al. (1978), is shown in Figure 2. Here, $\psi_{w}$ is the suction at wilting point (i.e. the suction limit at which a particular vegetation is unable to draw moisture from the soil), $\psi_{d}$ is the highest value of $\psi$ and $\psi_{a n}$ (soil suction at anaerobiosis point) is the lowest value of $\psi$ at $S=S_{\max }$, where $S_{\max }$ is the maximum rate of root water uptake. 
Docker and Hubble (2001), and Landsberg (1999), proposed that the total cross sectional area of roots, including the depth and distance from the trunk, can be determined by an exponential relationship. It is assumed by symmetry that the maximum root density lies on a circle with $r=r_{0}$ at a depth of $z=z_{0}$ (see Figure 3), and also that the root density decreases exponentially from this maximum value both vertically and radially. According to Indraratna et al. (2005), the root density function may be written as:

$\beta(r, z, t)=\beta_{\text {max }}(t) \cdot e^{-k_{1}\left|z-z_{0}(t)\right|-k_{2}\left|r-r_{0}(t)\right|}$

where, $\beta_{\max }(t)$ is the maximum root density at time $t$, and $k_{1}$ and $k_{2}$ are two empirical coefficients depending on the type and system of tree root.

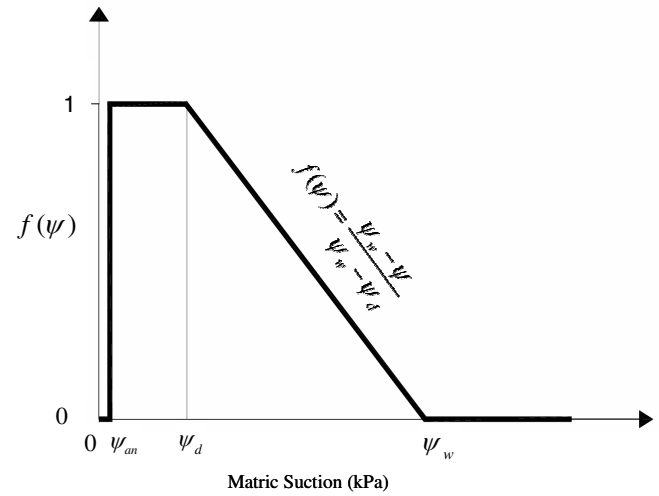

Figure 2. Soil suction factor (modified after Feddes et al., 1978)

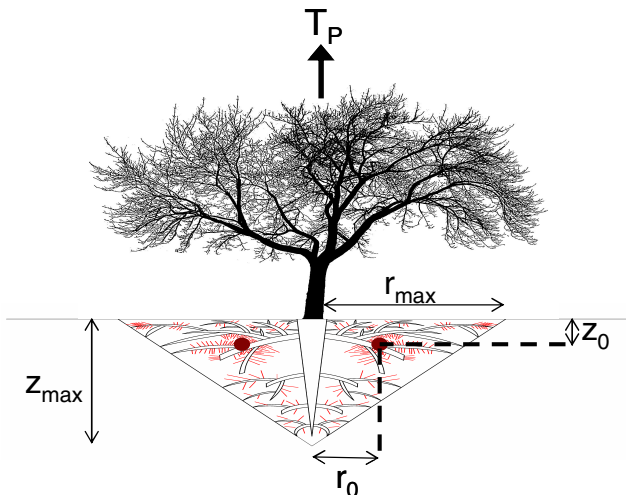

Figure 3. Schematic sketch of tree root zone

For a given transpiration rate, the rate of water uptake from any particular unit volume of wet soil is proportional to $\beta$. As suggested by Landsberg (1999), this relationship is nonlinear. Based on agronomical research, an asymptotic relationship may be assumed for the root water uptake. Nevertheless, there is an uncertainty in this relationship when the roots become widely separated, which can often be the case if the roots penetrate deeply into the soil.

Considering a hyperbolic tangent function that represents a nonlinear-asymptotic curve, the following equation is suggested by the authors for the root density factor, $G(\beta)$,

$$
G(\beta)=\frac{\tanh \left(k_{3} \beta\right)}{\int_{V(t)} \tanh \left(k_{3} \beta\right) d V}
$$

In the above expression, $k_{3}$ is an empirical coefficient. $G(\beta)$ is presented as a normalised function, where $\int_{V(t)} G(\beta) d V=1$. 
Referring to the model proposed by Nimah and Hanks (1973), it can be inferred that with depth, the potential transpiration is not distributed uniformly within the root zone and therefore a linear distribution for potential transpiration is more appropriate. Accordingly, Equation (6) is derived to take the effect of potential transpiration into account (Indraratna et al, 2005):

$$
F\left(T_{P}\right)=\frac{T_{P}\left(1+k_{4} \cdot z_{\max }-k_{4} \cdot z\right)}{\int_{V(t)} G(\beta)\left(1+k_{4} \cdot z_{\max }-k_{4} \cdot z\right) d V}
$$

where, $T_{p}$ is the rate of potential transpiration and $k_{4}$ is an empirical coefficient to represent the effect of depth on potential transpiration distribution. The denominator of Equation (6) represents the transpiration mass balance.

To summarise, Equation (3), which introduced the rate of root water uptake, $S(x, y, z)$, can now be estimated by multiplying the three independent functions that represent soil suction, $f(\psi)$, root density, $G(\beta)$, and potential transpiration, $F\left(T_{P}\right)$.

\section{Verification of the Proposed Model Using FE Analysis}

The validity of the mathematical model (Eqn. 3) for the rate of root water uptake is examined in conjunction with finite element analysis, by considering a selected case history. The moisture content measured in the vicinity of a $14 \mathrm{~m}$ high lime tree located in a mown grass area of Boulder clay in Milton Keynes (U.K), has been reported by Biddle (1983). Table 1 shows the estimated parameters used in the authors' finite element analysis, based on the available literature.

Table 1. Parameters applied in the finite element analysis

\begin{tabular}{|c|c|c|c|}
\hline Parameter & Value & Reference & Comments \\
\hline$\psi_{a n}$ & $4.9 \mathrm{kPa}$ & Feddes et al. (1978) & Clayey soil with air content of 0.04 \\
\hline$\psi_{w}$ & $1500 \mathrm{kPa}$ & Feddes et al. (1978) & $1500<\psi_{w}<2000 \mathrm{kPa}$ \\
\hline$\psi_{d}$ & $40 \mathrm{kPa}$ & Feddes et al. (1978) & $40<\psi_{d}<80 \mathrm{kPa}$ \\
\hline$\gamma$ & $21 \mathrm{kN} / \mathrm{m}^{3}$ & Powrie et. al (1992) & Typical value for Boulder clay \\
\hline$r_{\max }$ & $9 m$ & Biddle (1983) & $\begin{array}{l}\text { Estimated from field measurements } \\
\left(7 m<r_{\max }<11 m\right)\end{array}$ \\
\hline$z_{\max }$ & $1.5 \mathrm{~m}$ & Biddle (1983) & Estimated from field measurements \\
\hline$k_{s}$ & $10^{-10} \mathrm{~m} / \mathrm{s}$ & $\begin{array}{c}\text { Lehane and Simpson } \\
\text { (2000) }\end{array}$ & Typical value for Boulder clay \\
\hline$P I$ & 23 & Biddle (1983) & Measured \\
\hline$e_{0}$ & 0.60 & Powrie et. al (1992) & Typical value for Boulder clay \\
\hline$C_{c}$ & 0.13 & Skempton (1944) & Typical value for Boulder clay \\
\hline
\end{tabular}


As reported by Biddle (1983), a Wallingford soil moisture probe, incorporating a 70 milli-curie americium-241/beryllium source, was used to measure the moisture content. Also, five tubes were inserted along a single radius at varying distances from the trunk. These distances related to the height of the tree at the time of insertion, were $0.1 \mathrm{~h}, 0.2 \mathrm{~h}, 0.4 \mathrm{~h}, 0.8 \mathrm{~h}$, and a far-field tube at $2 \mathrm{~h}$ for comparison.

This numerical analysis is based on the basic effective stress theory of unsaturated soils incorporated in the ABAQUS finite element code. The effective stress in the unsaturated soil is given by Bishop (1959):

$\sigma_{i j}^{\prime}=\sigma_{i j}-u_{a} \delta_{i j}+\chi\left(u_{a}-u_{w}\right) \delta_{i j}$

where, $\sigma_{i j}^{\prime}$ is the effective stress of a point on a solid skeleton, $\sigma_{i j}$ is the total stress in the porous medium at the point, $u_{a}$ is the pore air pressure, $u_{w}$ is the pore water pressure, $\delta_{i j}$ is Kronecker's delta $\left(\delta_{i j}=1\right.$ when $i=j$ and $\delta_{i j}=0$ when $i \neq j$ ), and $\chi$ is the effective stress parameter attaining a value of unity for saturated soils and zero for dry soils. Bishop's effective stress concept for predicting shear strength and volume change in unsaturated soils has recently been discussed and validated by Khalili et al. (2004). As a further refinement, Khabbaz (1997) presented a relationship for $\chi$ as a function of matric suction and the air entry value. The degree of saturation is associated with matric suction through the soil - water characteristic curve (SWCC). The air entry value as related to the soil structure can be determined using SWCC.

The authors' theoretical model representing the rate of root water uptake distribution within the root zone was included in the FE analysis through appropriate Fortran subroutines. A two-dimensional plain strain finite element mesh with 4-node bilinear displacement and pore pressure elements (CPE4P) was used to model variations in the moisture content. The overall mesh consisted of 1326 nodes and 1250 elements. The boundary conditions of the finite element model are illustrated schematically in Figure 4. The flux boundary at the surface is controlled by both climatic conditions and soil properties. It is assumed in this study that rainfall and evaporation are in balance and thus a "no water in-flow" condition is applied at the surface. According to the field measurements reported by Biddle (1983), the initial pore water pressure can be assumed as hydrostatic with the watertable located $13 \mathrm{~m}$ below the surface. 


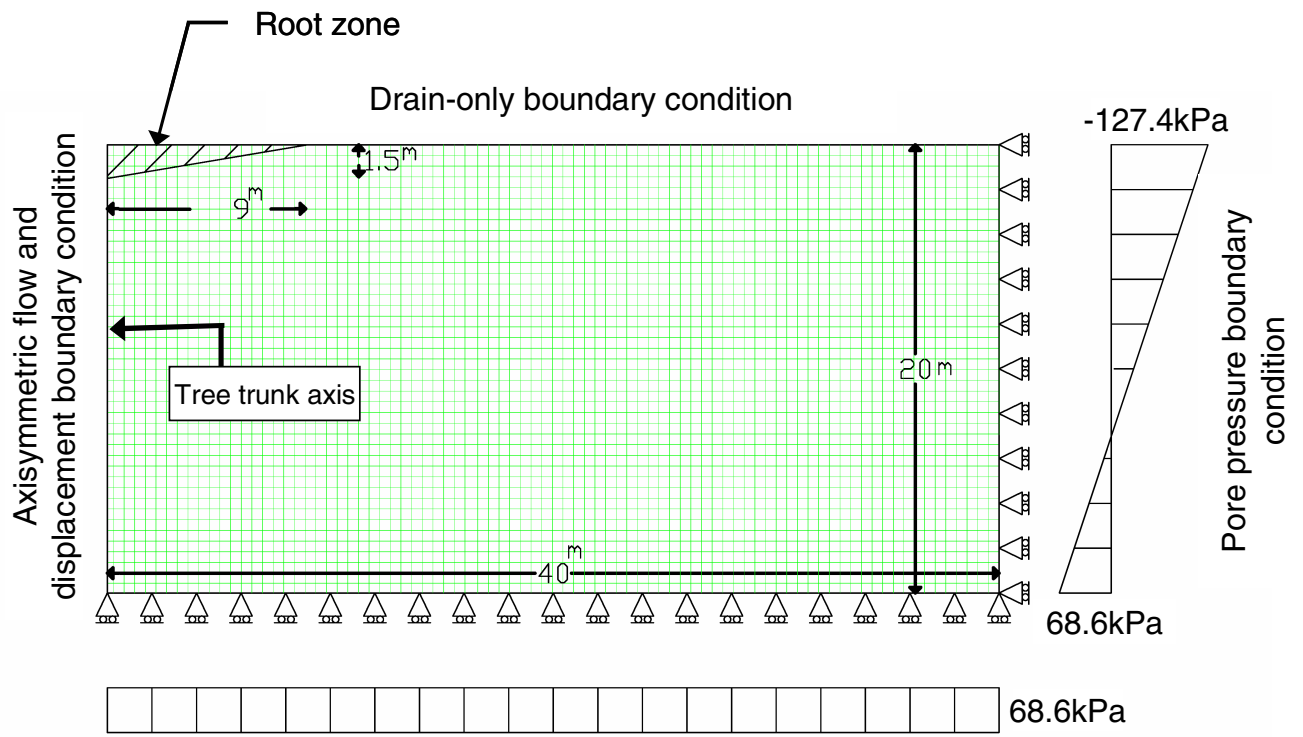

Pore pressure boundary condition

Figure 4. The geometry and boundary conditions of the verification model

The finite element analysis was conducted in two stages:

1) Geostatic: This stage is used to ensure that the analysis begins from a state of equilibrium under geostatic loading, following realistic initial conditions.

2) Consolidation: This represents a transient response of partially saturated soil under transpiration. In order to avoid non-physical oscillations and convergence problems caused by non-linearities, this stage included a timedependent analysis using 1 day intervals for 1-year, with continuous root water uptake.

The coefficient of unsaturated soil permeability has been calculated based on Brooks and Corey (1964), thus:

$k=k_{s}(e) \cdot S_{e}^{\frac{2+3 \lambda}{\lambda}}$

$S_{e}=\left[\frac{S_{r}-\left(S_{r}\right)_{\text {residual }}}{1-\left(S_{r}\right)_{\text {residual }}}\right]$

where, $k_{s}(e)$ is the saturated coefficient of permeability estimated based on the well known Kozeney-Carman equation (Mitchell, 1976), $S_{e}$ is the effective degree of saturation, $S_{r}$ is the degree of saturation, $\left(S_{r}\right)_{\text {residual }}$ is the residual degree of saturation, and $\lambda\left(=\Delta \log S_{e} / \Delta \log \psi\right)$ is the slope of the soil water characteristic curve on a log-log plot. 
The soil-water characteristic curve employed in this study is shown in Figure 5. A family of curves for different values of $w \times P I$ is shown in Figure 5, where $w$ is the fraction of soil passing sieve \#200 as an index between 0 to 1, and PI is the plasticity index (Zapata et al., 2000).

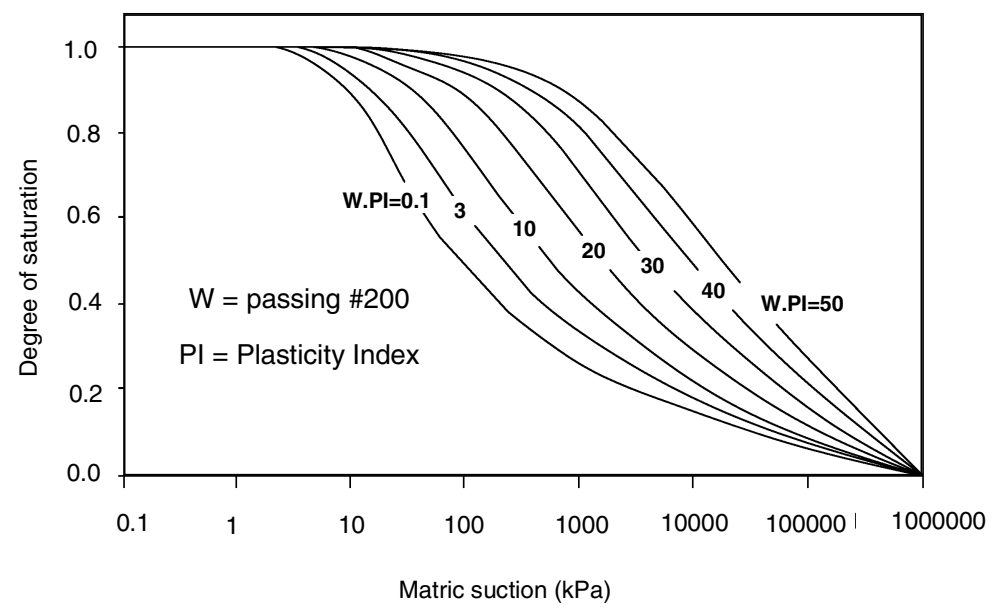

Figure 5. Predicted soil water characteristic curve based on $w \times P I$ (after Zapata et al., 2000)

As fluid passes through a porous medium, a coupled flow-deformation analysis of unsaturated soil is required to capture the 3-phase interaction among the soil, air, and water. The governing equations for pore fluid diffusion and deformation are a combination of Equation (2) and the relevant elasto-plastic deformation equations. The soil is Boulder clay whose behaviour can be defined by

$d e^{e l}=C_{c} \ln \left(\frac{p_{0}+d p}{d p}\right)$

where, $d e^{e l}$ denotes the change of void ratio in the element, $C_{c}$ is the compression index, $p_{0}$ is the initial mean effective stress, and $d p$ is the mean effective stress change on the soil skeleton. The effect of osmotic suction is assumed to be negligible. The material properties and parameters used in the finite element analysis were given earlier in Table 1, and the additional assumed parameters are given in Table 2.

Figure 6 shows a comparison between the field measurements and the numerically predicted reductions in the moisture content. The numerical results incorporating the authors' root water uptake model are in acceptable agreement with the field measurements reported by Biddle (1983). According to Figure 6, the field data is noticeably different from the finite element predictions around $6 \mathrm{~m}-8 \mathrm{~m}$ from the trunk. 
Table 2. Parameter values assumed in the finite element analysis in the verification model

\begin{tabular}{|c|c|c|}
\hline Parameter & Value & Comments \\
\hline$r_{0}$ & $6 \mathrm{~m}$ & $\begin{array}{l}\text { Radial coordinate of the maximum root } \\
\text { density point }\end{array}$ \\
\hline$z_{0}$ & $0.50 \mathrm{~m}$ & $\begin{array}{l}\text { Vertical coordinate of the maximum root } \\
\text { density point }\end{array}$ \\
\hline$\beta_{\max }(t)$ & $25 \mathrm{~m}^{-2}$ & $\begin{array}{l}\text { Taken from the general shape or root } \\
\text { suggested by Landsberg (1999) }\end{array}$ \\
\hline$k_{3}$ & $0.0874 \mathrm{~m}^{-1}$ & As above \\
\hline$k_{4}$ & 0.014 & $\begin{array}{l}\text { Coefficient of potential transpiration } \\
\text { distribution }\end{array}$ \\
\hline$k_{1}$ & 10 & Coefficient of vertical root distribution \\
\hline$k_{2}$ & 0.30 & Coefficient of horizontal root distribution \\
\hline$v$ & 0.30 & Typical value for clayey soils \\
\hline$T_{P}$ & $3 \mathrm{~mm} /$ day & Rate of potential transpiration \\
\hline Passing \#200 & $55 \%$ & Typical value for Boulder clay \\
\hline
\end{tabular}

This is not surprising given the simplicity of the assumptions with regard to the shape of the root zone. Furthermore, as the foliage alters the uniform distribution of rainfall, the moisture content is expected to increase at the canopy edges (say approximately $6 \mathrm{~m}-8 \mathrm{~m}$ from the tree trunk), which will probably contribute to the disparity between the field data and finite element predictions. It is also important to note that a homogeneous profile has been assumed in the numerical analysis although a heterogeneous profile can influence root distribution, which in turn significantly affects moisture distribution and content. In Figure 6(b), the soil is assumed to be homogeneous, whereas in Figure 6(a), the actual field data is probably influenced by the heterogeneity of the soil.

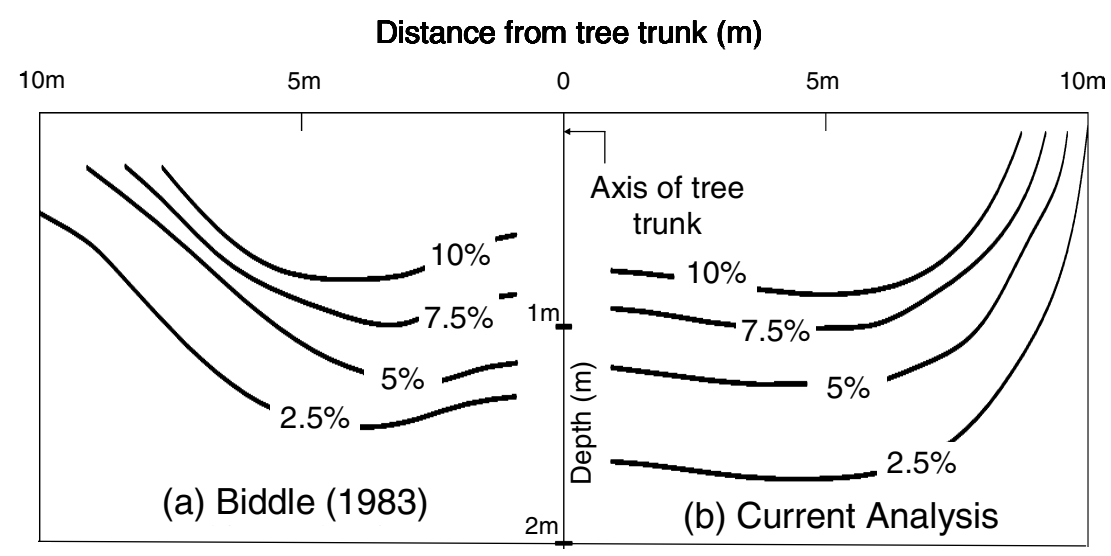

Figure 6. Contours of volumetric soil moisture content reduction (\%) in the vicinity of a lime tree (a) Biddle (1983) (b) current finite element analysis 
The predicted steady state matric suction profile at $0,0.5,1$, and $1.5 \mathrm{~m}$ deep based on finite element analysis, is presented in Figure 7, where the maximum change in the soil matric suction occurs $0.5 \mathrm{~m}$ deep, which is also the location of the maximum root density (i.e. $z=z_{0}=0.5 \mathrm{~m}$ ).

Figure 8 shows the ground settlement at various depths, where only the suction related settlement was considered in this study. The results show that after one year of continuous transpiration, the rate of change in matric suction $(d \psi / d t)$ is less than $10^{-6} \mathrm{kPa} / \mathrm{s}$, which is considered to be the steady state (equilibrium) condition. As expected, the ground settlement would decrease rapidly with the sub-surface distance. On the surface, the $80 \mathrm{~mm}$ vertical settlement by the tree trunk decreases to about $20 \mathrm{~mm}, 10 \mathrm{~m}$ away from the trunk (Figure 8). As shown in Figure 8, the location of the maximum settlement is closer to the trunk at shallower depths, which almost coincides with the point of maximum suction (see Figure 3).

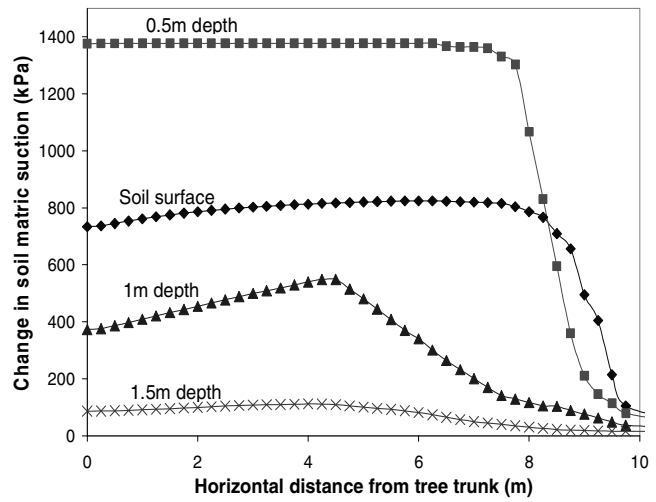

Figure 7. Predicted soil matric suction in different depths

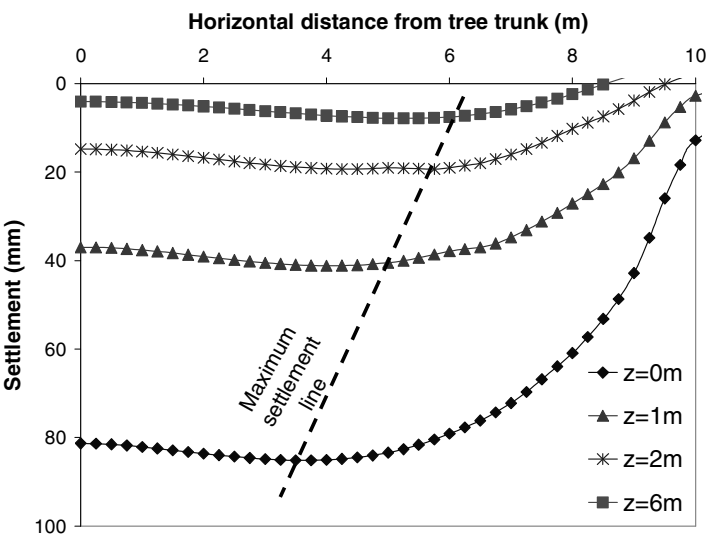

Figure 8. Ground settlement at various depths

\section{Conclusions}

Given the importance of the vadose zone in most geo-environmental projects, there is a strong need to develop a better understanding of how trees, including natural vegetation, influence behaviour within this zone. A mathematical model was developed for predicting the rate of root water uptake, which takes into account soil matric suction, and distribution of root density and potential transpiration. The proposed model was used in a numerical analysis with the ABAQUS finite element code to examine the content and distribution of moisture in the soil near a tree. In the analysis of the selected case history (a single lime tree), this mathematical model was used to find the distribution and rate of root water uptake. In spite of uncertainties in the assumptions of the soil parameters, root distribution and atmospheric parameters, a good agreement was obtained between the measured and simulated distribution of moisture. The results of this study provide a valuable and relatively accurate means of estimating the influence of vegetation on ground conditions. The numerical model developed herein offers practicing geotechnical engineers a powerful tool for 
designing structures on the vadose zone, which are under the influence of native vegetation. It may be noted that the role of the root zone as natural reinforced soil was not implemented in the model described in this paper.

\section{Acknowledgement}

This research was conducted under the auspices of the Australian Cooperative Research Centre for Railway Engineering and Technologies (Rail-CRC). Support of ARTC and Dr. Don Cameron (University of South Australia) is appreciated. A substantial part of the content presented in this paper has been reported in greater detail in Geotechnical Engineering, proceedings of ICE (UK) to be published in the near future.

\section{References}

Biddle, P.G. (1983). "Pattern of soil drying and moisture deficit in the vicinity of trees on clay soils." Geotechnique, 33(2), 107-126

Bishop, A.W. (1959). "The principle of effective stress." Teknish Ukebadk, Norway, 1959, No. 39, 859-863

Brooks, R.H., and Corey, A. T. (1964). "Hydraulic properties of porous media." Hydrology paper3, Colorado state university, Fort Collins, Colorado

Docker, B.B. and Hubble, T. C. T. (Ho \& Li (Eds.)) (2001). "Strength and Distribution of Casuarinas Glauca Roots in Relation to Slope Stability." Geotechnical Engineering, Swets \& Zeitlinger, 745-749.

Feddes, R.A., Kowalik, P. J. and Zaradny, H. (1978). Simulation of field water use and crop yield. Simulation Monograph. Pudoc, Wageningen, 9-30

Indraratna, B., Fatahi, B. and Khabbaz, M. (2005). " Numerical Analysis of Matric Suction Effects Induced by Tree Roots." Geotechnical Engineering - Proceedings of the Institution of Civil Engineers (provisionally accepted).

Khabbaz M. H. (1997). "An effective stress theory based numerical model for flow and deformation in unsaturated soils." PhD thesis, University of New South Wales, Sydney.

Khalili N. Geiser F. and Blight G E. (2004). "Effective stress in unsaturated soils: Review with new evidence." Int. J. of Geomechanics, 4(2), 115-126

Landsberg J. J. (1999). "Tree Water Use and its Implications in Relation to Agroforestry Systems." RIRDC, Australia, RIRDC Publication No. 99/37, 1-24

Lehane, B.M. and Simpson, B. (2000). "Modelling glacial till under triaxial conditions using a BRICK soil model." Canadian Geotechnical J., 37, 1078-1088

McKeen, R.G. (1992). "A model for predicting expansive soil behaviour." Proc. 7th International Conference on Expansive Soils, Dallas, Vol. 1, 1-6

Mitchell, J.K. (1976). Fundamentals of soil behaviour. John Wiley \& Sons, Inc. U.S.A, 348 
Nimah, M.N., and Hanks, R. J. (1973). "Model for estimating soil water, plant and atmospheric interrelations. I. description and sensitivity." Proceedings of Soil Science Society of America, 37, 522-527

Powrie, W., Davies, J.N., and Britto, A. M. (1992). "A cantilever retaining wall supported by a berm during temporary work activities." ICE conference on retaining structures, Robinson College, Cambridge, 418-428

Skempton, A.W. (1944). "Notes on compressibility of clays." Quarterly Journal of Geological Society, London, 100(2), 119-135

Zapata, C.E., Houston, W. N., Houston, S. L., and Walsh, K. D. (Shackeford, Houston, and Chanh (Eds.).) (2000). "Soil-water characteristic curve variability." Advances in unsaturated geotechnics, ASCE, Geotechnical Special Publication, No. 99, 84-124

Zhang, L.L., Fredlund, D.G., Zhang, L.M., and Tang, W.H. (2004). "Numerical study of soil conditions under which matric suction can be maintained." Canadian Geotechnical Journal, 41, 569-582 